International Journal Of Mechanical Engineering And Information Technology

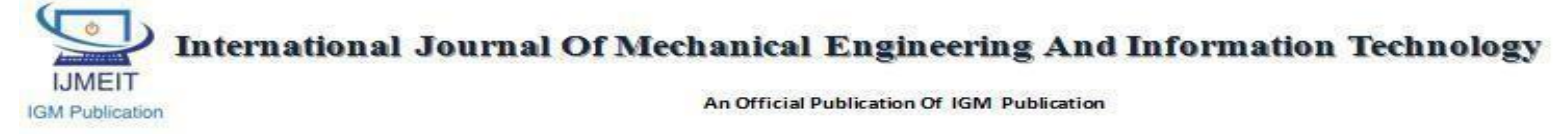

\title{
Identifying Standardized Data for Manufacturing Commercial Grade Pencils Made Out of Recycled or Waste Paper with Qualities Comparable to Wooden Pencils
}

\author{
Authors \\ Mrigank Sinha ${ }^{1}$ \\ ${ }^{1}$ B.E. Mechanical Engineering, Manipal Institute of Technology, Manipal, India \\ Email: mrigank29@gmail.com
}

\begin{abstract}
-
Pencils made out of waste or recycled paper is a new concept and is trending throughout the world. The aim of this product is to recycle paper and reduce cutting of trees by substituting wooden pencils. The technology of manufacturing pencils out of waste paper is new. It involves wrapping the paper around the graphite core using a suitable adhesive so that proper strength and desired properties equivalent to a wooden pencil can be achieved. This is done on a rolling machine comprising of a motor driven belt and 2 pressure plates which make the paper roll around the core due to friction between the belt and plates. Various types of paper can be used to make this product. Although the idea is unique, many problems are faced while trying to make a commercial grade product comparable to the wooden pencils. The first aim of this paper is explaining the process of manufacturing, pointing out the problems faced during manufacturing of commercial grade paper pencils and offer solutions to achieve a quality comparable to wooden pencils by providing empirical evidence. The second aim is to provide standardized data of manufacturing paper pencils after solving the problems faced in the process. First, the problems faced with the quality of paper pencils were identified and experiments were conducted by varying parameters to obtain a solution. Second, manufacturing data from 10 weeks was collected after fixing the problems with quality to obtain standardized manufacturing data for future production.

Keywords- core sticking, GSM, paper pencil, papertree, pencil rolling machine
\end{abstract}

\section{INTRODUCTION}

14 billion wooden pencils are made all over the world each year. One tree can produce 170,000 pencils on an average which adds up to 82,000 trees that are cut every year to meet the annual demand of 14 billion pencils. $30-40 \%$ of municipal waste is paper and $50 \%$ of office waste is paper which ends up in landfills. Nearly half $(42 \%)$ of all the global wood harvest is destined to become paper. Every US household throws out an equivalent of 4 trees in paper waste per annum. Recycling one ton of paper saves 20 trees, 7,000 gallons of water, three cubic yards of landfill space, and 60 pounds of air pollutants and saves enough energy to power an average home for 6 months. A minimum of 20 pencils can be manufactured by using a single newspaper that we read daily. Papertree Creations India Pvt. Ltd., a startup incubated under MUTBI
(Manipal University Technology Business Incubator), worked towards manufacturing of commercial grade pencils made out of recycled paper in order to substitute wooden pencils in the market. This paper explains each stage of manufacturing process with empirical data of over 10 weeks, highlights the problems with quality of paper pencils when compared to wooden pencils and provides solution based on the experimental data and observations.

\section{METHODOLOGY OF MANUFACTURING PAPER PENCILS}

The manufacturing of paper pencils was found to be a multistage process. The process starts with selecting the recycled paper and cutting it into required length to achieve the desired diameter. 
Then, the lead core is pasted on the paper and it is rolled using a rolling machine with an adhesive feeder mechanism. The rolled pencils are then dried and finished to achieve the final product. The final product is then tested to make sure it has qualities similar to wooden pencils. The layout of the process has been shown in figure 1 .

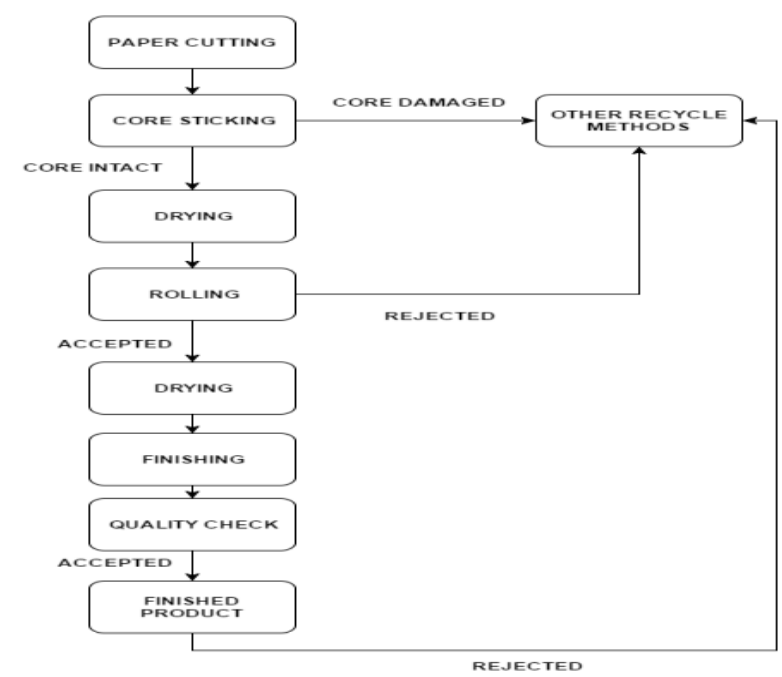

Fig.1. Flowchart depicting processes involved in manufacturing of paper pencils

\subsection{Paper cutting}

The first process in the production line is paper cutting. First, the type of paper to be used is decided. Once that is done the length of the paper to be cut is determined according to the GSM( gram per meter square) of the paper to get the desired diameter while rolling. Then, the paper cutting machine is used to cut the paper in the already decided size. As the GSM of the paper increases the length of the paper to be cut decreases. Table. 1 shows GSM ranges for various types of papers that can be recycled after daily use.

\section{Table.1 GSM of various types of papers}

\begin{tabular}{|l|l|}
\hline Types of recycled papers & $\begin{array}{l}\text { GSM (gram per meter } \\
\text { square) }\end{array}$ \\
\hline Recycled paper & $30-60$ \\
\hline Chart paper & $65-120$ \\
\hline Newspaper & 56 \\
\hline Magazine paper (coated) & $90-120$ \\
\hline A4 printing paper & 85 \\
\hline
\end{tabular}

\subsection{Core sticking}

After the paper is cut to the required size, white latex adhesives are used to stick graphite leads on the paper Excessive use of adhesive was avoided as it hindered the rolling process making the paper difficult to roll. At the same time, it was made sure that the binding strength was strong enough to ensure that the lead does not come out after rolling. After this process, the pasted graphite lead were left to dry for 2 hours before rolling them in the rolling machine.

\subsection{Rolling process}

Rolling was done on a customized semi-automatic rolling machine. The machine consisted of a corrugated belt made of synthetic polymer rolling around two rollers $1.26 \mathrm{~m}$ apart. The driving roller was connected at the receiving end of the machine which was connected to a worm and worm wheel reduction unit and a motor as explained in Fig.2. Two pressure plates were mounted on top of the synthetic belt on the machine as shown in Fig.3. The pressure applied by the pressure plates was maintained by a screw spring mechanism. An adhesive feeding unit along with a roller for spreading the adhesive over the paper is also shown in Fig.3. The paper after core sticking was fed manually in the rolling machine in the direction of the belt movement, which went under the adhesive feeder and through the idle roller meant to spread glue all over the paper. The paper with lead facing first would the go under the pressure plated forcing the paper to roll over the lead. A second pressure plate was put to make sure complete rolling of the paper. The maximum rolling length that could be achieved using the pressure plates was $690 \mathrm{~mm}$. The rolled pencil was then collected at the other side of the rolling machine and put for drying.

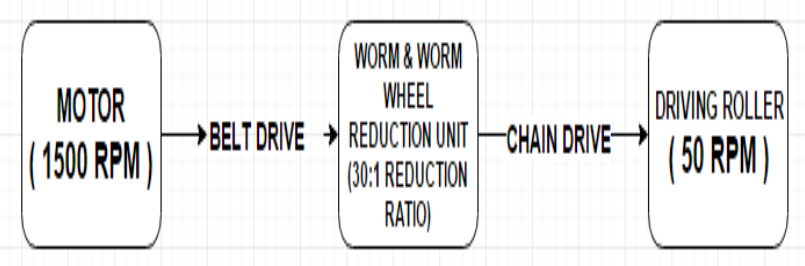

Fig.2 Driving mechanism in the rolling machine 


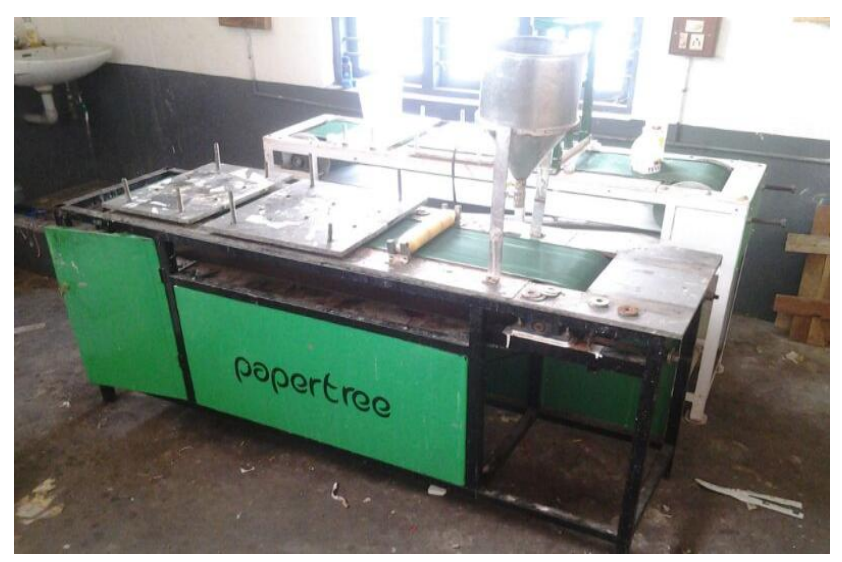

Fig.3. Rolling machine

\subsection{Drying}

After the units are put in the drying rack they were left for drying in the sunlight for 6 hours. Then they were put in the dryer for further heating to ensure removal of moisture. Pencils were heated at 150 degree Celsius for 12-15 minutes.

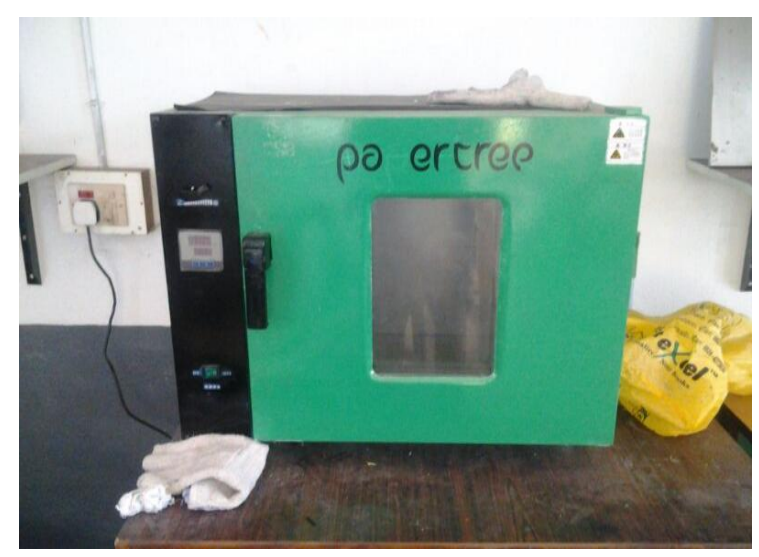

Fig.4. Dryer

\subsection{Finishing}

The first process was polishing the dried rolled pencils using sand paper. Polishing was required due to the uneven drying of adhesive on the surface of the pencil. The second process was an optional one. A shrink wrap with a customized printed message could be put on the pencil and the pencil could be dried in the dryer for 2 minutes at 80 degree Celsius. The shrink wrap would take the cylindrical shape of the pencil. The third step in the finishing process was end cutting. The pencils were cut from both ends to maintain a uniform length in all pencils. After the finishing process was completed, all the finished units went for quality check. The finished paper pencil without shrink wrap is shown in Fig.5.

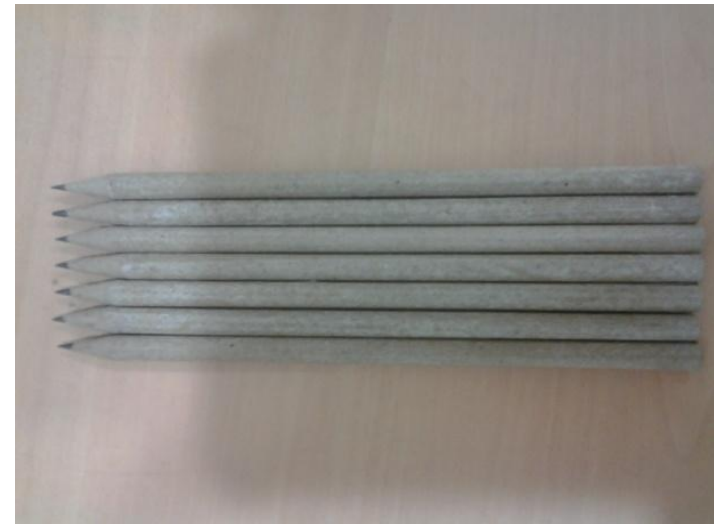

Fig.5. Finished paper pencils without shrink wrap

\subsection{Quality check}

After the paper pencils were finished, the following quality tests were done:

- The length of each pencil was checked and it was checked whether the end cutting was uniform.

- A mechanical gauge was used to measure the diameter of each pencil. The tolerance range set was 7.6-8 $\mathrm{mm}$. Any units falling outside the range were rejected.

- Hardness test was performed on every pencil by measuring the Vickers Hardness Number. Wooden pencils had a hardness number of 12. Thus, pencils with hardness number less that 12 were rejected.

- A manual check was done to make sure that the lead adhered to the paper strongly and wouldn't come out after rolling.

- The final test was the sharpening test. Standard wooden pencils sharpeners were used to sharpen paper pencils. If the sharpening results were not satisfactory, the pencils were rejected.

\section{QUALITY OBSERVATIONS}

Two serious quality issues were observed after the finished products were checked. The issues are listed below.

- Hardness of the pencil varied and the required hardness was not achieved. $50 \%$ of the pencils failed the hardness test. The paper pencils became soft and would bend easily breaking the lead core. 
- $90 \%$ of the paper pencils failed the sharpening test. Either the sharpener was soiled after 3-4 pencils or the pencils wouldn't sharpen at all. Without the ability of being sharpened, the concept of paper pencils was failing.

\section{RESULT AND ANALYSIS}

To find a solution for the quality issues, two major parameters in the manufacturing of paper pencils were identified. These factors were the quality of paper according to GSM (gram per square meter) and the type of adhesive being used. A range of papers from GSM between 44 and 90 were taken and were rolled using a variety of non harmful adhesives- two types of potato starch based adhesives, 3 types of synthetic resin adhesives, wheat based adhesive and egg based adhesive. A batch of 50 units was made for each GSM of paper and adhesive type. The observations were recorded.

\subsection{Hardness test}

This experiment was done by rolling each type of paper with different types of adhesives and average Vickers hardness number for each batch was noted. The batch with average Vickers hardness number greater than 12 was approved and the paperadhesive type were accepted. Table. 2 shows the results of the test conducted.

\section{Table.2- Vickers Hardness Number of various batches prepared}

\begin{tabular}{|l|l|l|l|l|l|l|}
\hline Vickers hardness number of finished product & \multicolumn{7}{l|}{ Paper by GSM (gram per meter square) } \\
\cline { 2 - 8 } Types of adhesives & 44 & 50 & 56 & 70 & 75 & 90 \\
\hline Potato starch based adhesive (kores) & 8.12 & 9.65 & 9.75 & 12.78 & 18.1 & 18.7 \\
\hline Potato starch based adhesive (camel) & 8.3 & 9.48 & 9.72 & 11.93 & 16.87 & 17.8 \\
\hline Synthetic resin adhesive ( fevicol) & 8.94 & 12 & 12.07 & 13.83 & 16.91 & 18.2 \\
\hline Synthetic resin adhesive ( tricol) & 8.86 & 12.09 & 12.61 & 15.21 & 18.56 & 19.12 \\
\hline Synthetic resin adhesive- very low viscosity ( henkel) & 8.36 & 9.75 & 10.07 & 11.65 & 15.74 & 17.02 \\
\hline Wheat based adhesive & 8.21 & 8.87 & 9.34 & 11.2 & 11.8 & 13.84 \\
\hline Egg based adhesive & 7.96 & 8.49 & 8.84 & 9.63 & 10.92 & 13.04 \\
\hline
\end{tabular}

It was inferred from the observations that papers with GSM values of less than 50 failed the hardness test with all types of adhesives. Synthetic resin adhesive was able to achieve required hardness in papers with GSM value of 50 or greater. Potato starch based adhesives were able to achieve required hardness in papers with GSM value 70 or greater. Wheat based and egg based adhesives could only provide required hardness for papers with a GSM value of 90 .

4.2 Sharpening test

The batch of pencils after hardness test was checked for sharpening using standard wooden pencil sharpeners. The data observed was marked as "PASS" if satisfactory and "FAIL" if unsatisfactory. These data are shown in Table.3.

\section{Table.3 Sharpening test of various batches prepared}

\begin{tabular}{|l|l|l|l|l|l|l|}
\hline Sharpening test & \multicolumn{5}{|l|}{$\mid$} \\
\hline \multirow{2}{*}{ Types of adhesives } & \multicolumn{2}{l|}{ Paper by GSM ( gram per meter square) } \\
\cline { 2 - 8 } & 44 & 50 & 56 & 70 & 75 & 90 \\
\hline Potato starch based adhesive (kores) & fail & fail & fail & pass & pass & fail \\
\hline Potato starch based adhesive (camel) & fail & fail & fail & pass & pass & fail \\
\hline Synthetic resin adhesive ( fevicol) & fail & pass & pass & pass & pass & fail \\
\hline Synthetic resin adhesive ( tricol) & fail & pass & pass & pass & pass & fail \\
\hline Synthetic resin adhesive- very low viscosity ( henkel) & fail & fail & fail & fail & fail & fail \\
\hline Wheat based adhesive & fail & fail & fail & fail & fail & fail \\
\hline Egg based adhesive & fail & fail & fail & fail & fail & fail \\
\hline
\end{tabular}


It was inferred from the observations that pencils made from potato based adhesives could be sharpened if the GSM of papers was between 70 and 75 while pencils made from synthetic resin adhesives could be sharpened if the GSM of papers was between 50 and 75 . Pencils made from synthetic resin with very low viscosity, wheat based adhesive and egg based adhesives couldn't be sharpened.

\subsection{Standardized manufacturing data}

After analyzing the results from the hardness and sharpening test, it was inferred that paper pencils Table.4 Paper cutting data that satisfy both tests were made from synthetic resin adhesives and were made from papers with GSM values of 50 to 75 . By selecting these two parameters, data was collected for a period of 10 weeks of production and standard data was collected. These data included time taken from each process, adhesive usage per pencil and percentage of rejection.

\section{a. Paper cutting data}

Table. 4 shows the standard data of paper cutting obtained from 10 weeks of production.

\begin{tabular}{|c|c|c|c|}
\hline \multicolumn{4}{|c|}{ Paper cutting data } \\
\hline Week & $\begin{array}{l}\text { Average number of units } \\
\text { prepared per person }\end{array}$ & $\begin{array}{l}\text { Average time taken in } \\
\text { minutes }\end{array}$ & $\begin{array}{l}\text { Units cut in } 1 \\
\text { minute }\end{array}$ \\
\hline 1 & 1500 & 260 & 5.77 \\
\hline 2 & 1550 & 270 & 5.74 \\
\hline 3 & 1400 & 308 & 4.55 \\
\hline 4 & 1550 & 270 & 5.74 \\
\hline 5 & 1500 & 285 & 5.26 \\
\hline 6 & 1810 & 452 & 4.00 \\
\hline 7 & 2050 & 346 & 5.92 \\
\hline 8 & 2699 & 460 & 5.87 \\
\hline 9 & 3104 & 525 & 5.91 \\
\hline \multirow[t]{2}{*}{10} & 1620 & 278 & 5.83 \\
\hline & & Average & 5.46 \\
\hline
\end{tabular}

It was inferred from Table. 4 that 5.46 units of paper were cut in 1 minute. Therefore, it was concluded that a batch of 500 units could be cut in 91.57 minutes. Thus, approximately 1.5 man hours are required for cutting of 500 units.

\section{b. Core sticking data}

It was inferred from Table.5 that 2.82 units were pasted in 1 minute. Therefore, it was concluded that a batch of 500 units could be pasted in 177.3 minutes. Thus, approximately 3 man hours are required for pasting of 500 units.

\section{Table.5 Core sticking data}

\begin{tabular}{|l|l|l|l|}
\hline \multicolumn{2}{|l|}{ Core sticking data } \\
\hline $\begin{array}{l}\text { Average number of units } \\
\text { prepared per person }\end{array}$ & $\begin{array}{l}\text { Average time taken in } \\
\text { minutes }\end{array}$ & $\begin{array}{l}\text { Units pasted in 1 } \\
\text { minute }\end{array}$ \\
\hline 1 & 300 & 187 & 1.60 \\
\hline 2 & 590 & 386 & 1.53 \\
\hline 3 & 2020 & 806 & 2.51 \\
\hline 4 & 1516 & 425 & 3.57 \\
\hline 5 & 553 & 180 & 3.07 \\
\hline 6 & 1481 & 469 & 3.16 \\
\hline 7 & 1568 & 512 & 3.06 \\
\hline
\end{tabular}




\begin{tabular}{|l|l|l|l|}
8 & 1425 & 489 & 2.91 \\
\hline 9 & 1532 & 525 & 2.92 \\
\hline 10 & 1683 & 435 & 3.87 \\
\hline & & Average & 2.82 \\
\hline
\end{tabular}

\section{c. Rolling data}

It was inferred from Table.6 that the average percentage of rejection during rolling process was $4.32 \%$. Thus, in order to manufacture 500 paper pencils, approximately 522 units had to be rolled. The average adhesive usage per pencil was $2.02 \mathrm{ml}$. Thus, in order to make 500 paper pencils, 1.01 litres of adhesives would be used.
A pencil was rolled at every 0.15 minute. Therefore, it could be concluded that on an average one pencil was rolled in 9 seconds. Thus, approximately 6.67 pencils were rolled every minute. Therefore, it was concluded that a batch of 500 units could be rolled in 74.96 minutes. Thus, approximately 1.25 man hours are required for rolling 500 units.

\section{Table.6 Rolling data}

\begin{tabular}{|c|c|c|c|c|c|c|c|}
\hline \multicolumn{8}{|c|}{ Rolling data } \\
\hline Week & $\begin{array}{l}\text { Actual } \\
\text { rolled }\end{array}$ & Rejected & $\begin{array}{l}\% \text { of } \\
\text { rejection }\end{array}$ & $\begin{array}{l}\text { Adhesive } \\
\text { use (in ml) }\end{array}$ & $\begin{array}{l}\text { Adhesive usage } \\
\text { per pencil (in } \\
\text { ml) }\end{array}$ & $\begin{array}{l}\text { Time } \\
\text { (in } \\
\text { min) }\end{array}$ & $\begin{array}{lr}\text { Time } & \text { per } \\
\text { pencil } & \text { (in } \\
\text { min) } & \end{array}$ \\
\hline 1 & 437 & 52 & $11.90 \%$ & 1450 & 3.32 & 95 & 0.22 \\
\hline 2 & 1702 & 106 & $6.23 \%$ & 3270 & 1.92 & 279 & 0.16 \\
\hline 3 & 1687 & 41 & $2.43 \%$ & 3320 & 1.97 & 271 & 0.16 \\
\hline 4 & 1971 & 26 & $1.32 \%$ & 2650 & 1.34 & 265 & 0.13 \\
\hline 5 & 507 & 0 & $0.00 \%$ & 800 & 1.58 & 60 & 0.12 \\
\hline 6 & 2056 & 75 & $3.65 \%$ & 3900 & 1.90 & 308 & 0.15 \\
\hline 7 & 2192 & 82 & $3.74 \%$ & 4020 & 1.83 & 315 & 0.14 \\
\hline 8 & 2068 & 69 & $3.34 \%$ & 4000 & 1.93 & 290 & 0.14 \\
\hline 9 & 2259 & 105 & $4.65 \%$ & 4200 & 1.86 & 325 & 0.14 \\
\hline 10 & 1744 & 104 & $5.96 \%$ & 4500 & 2.58 & 238 & 0.14 \\
\hline \multicolumn{3}{|c|}{ Average } & $4.32 \%$ & & 2.02 & & 0.15 \\
\hline
\end{tabular}

\section{d. Finishing data}

It was inferred from Table.7 that 2.15 units were finished in one minute. Therefore, it was concluded that a batch of 500 units could be finished in 232.55 minutes. Thus, approximately 4 man hours are required for finishing of 500 units.

\section{Table.7 Finishing data}

\begin{tabular}{|l|l|l|l|}
\hline \multicolumn{2}{|l|}{ Finishing data } \\
\hline Week & $\begin{array}{l}\text { Average number of units } \\
\text { prepared per person }\end{array}$ & $\begin{array}{l}\text { Average time taken in } \\
\text { minutes }\end{array}$ & $\begin{array}{l}\text { Units stuck in 1 } \\
\text { minute }\end{array}$ \\
\hline 1 & 437 & 185 & 2.36 \\
\hline 2 & 1702 & 792 & 2.15 \\
\hline 3 & 1687 & 870 & 1.94 \\
\hline 4 & 1971 & 924 & 2.13 \\
\hline 5 & 507 & 190 & 2.67 \\
\hline 6 & 2056 & 930 & 2.21 \\
\hline
\end{tabular}




\begin{tabular}{|l|l|l|l|}
7 & 2192 & 1015 & 2.16 \\
\hline 8 & 2068 & 1005 & 2.06 \\
\hline 9 & 2259 & 1190 & 1.90 \\
\hline 10 & 1400 & 725 & 1.93 \\
\hline & & Average & 2.15 \\
\hline
\end{tabular}

\section{CONCLUSION AND FUTURE SCOPE}

\subsection{Conclusion}

The experimental data provided in this paper can be used to manufacture commercial grade paper pencils and replace wooden pencils. It provides solution to two problems faced while manufacturing pencils- hardness and ability to be sharpened. By using papers with GSM from 50 to 75 with synthetic resin adhesives, these two problems can be overcome. In addition, the paper provides standardized data that can be used by anyone to manufacture paper pencils. According to the data collected, in order to manufacture 500 units of paper pencil, it would take 1.01 litres of adhesive and 9.75 man hours.

Few points are needed to be kept in mind while manufacturing paper pencils. Slight variation in paper cutting can give a bad taper which leads to rejection of units. Poor core sticking could lead to a non uniform roll which could again lead to rejection and the chances of the core coming out while writing increases. Overheating of pencils can cause over drying which results in poor sharpening. Imperfection in the blade during end cutting could cause non uniform cut .A rough surface finish could result in poor printing quality.

\subsection{Future scope}

A semi-automatic paper cutter can be used to cut paper as it can cut 200 sheets at once which is 10 times the speed of a manual paper cutter which cuts 20 sheets at once.

End cutting can be mechanized using a marble cutter working mechanism which will ensure smoother and faster cuts thus increasing productivity and reducing time.

A glue collection mechanism can be fit on the receiving end of the rolling machine which would help in reusing the glue which would have gone to waste. This increases productivity.
A new roller can be put in the rolling machine with holes which can supply adhesive directly on to the belt thus ensuring better spreading of adhesive. This will ensure better hardness and sharpening.

Different properties of adhesives can be exploited to manufacture a composite adhesive which provides better hardness.

\section{REFERENCES}

1. Su Shin-Dih (Taiwan), Patent Number: 6,139,671, Date of Patent: Oct. 31, 2000, Method for manufacturing pencils having a paper-made cylinder

2. George W. Denman (US); Samuel J.Homes (US), James L. Rose (US), Patent Number: 5,417,786, Date of Patent: May 23, 1995, Apparatus and method for coating and wrapping pipe

3. Kay Miller (US), Patent No.: 369,789, Date of Application: December 12, 1940, Machine and method for making paper wrapped pencils

4. Inventor - Unknown, Indian Patent Number - WO 2011073999 A2, Bio degradable writing instrument and process for making the same.

5. Mike Maksymkiw, Gary Haider, Michael Dochniak, Leonard Jannusch, Paul Wade, Patent Number: US5624758 A, Date of Patent: April 29, 1997, Water based adhesives having enhanced characteristics

6. A.J. Kinloch, Adhesion and adhesivesscience and technology (Chapman and Hall,1987)

7. John F Murphy, Omdahl Russel, Patent Number: US2486756A, Synthetic resin adhesive 
8. Karl Heinz Bosch, Patent Number: WO2010091833A1, Method for production of paper pen/pencil

9. Vijay Patel, Daniel W. Wuerch, Patent number: EP0981587A1, Date of Patent: March 1, 2000, Fast setting polychloroprene adhesives.

10. Irving Skeist, Handbook of adhesives-third edition ( Chapman and Hall,1990) 